\title{
A Case of Hemophagocytic Lymphohistiocytosis Triggered by Disseminated Tuberculosis and Hairy Cell Leukaemia after SARS-CoV2 Infection
}

\author{
Alessandro Cellini ${ }^{1,+}$, Andrea Visentin ${ }^{1,2,+}{ }^{(D}$, Massimiliano Arangio Febbo ${ }^{1}$, Susanna Vedovato ${ }^{1}$, \\ Serena Marinello ${ }^{3}$, Ivo Tiberio ${ }^{4}$, Livio Trentin ${ }^{1,2, * \mathbb{D}}$ and Carmela Gurrieri ${ }^{1}$
}

Citation: Cellini, A.; Visentin, A.; Arangio Febbo, M.; Vedovato, S.;

Marinello, S.; Tiberio, I.; Trentin, L.;

Gurrieri, C. A Case of

Hemophagocytic

Lymphohistiocytosis Triggered by

Disseminated Tuberculosis and Hairy

Cell Leukaemia after SARS-CoV2

Infection. Appl. Sci. 2022, 12, 564

https://doi.org/10.3390/

app12020564

Academic Editor: Laura Porretti

Received: 3 November 2021

Accepted: 5 January 2022

Published: 7 January 2022

Publisher's Note: MDPI stays neutral with regard to jurisdictional claims in published maps and institutional affiliations.

Copyright: (C) 2022 by the authors. Licensee MDPI, Basel, Switzerland. This article is an open access article distributed under the terms and conditions of the Creative Commons Attribution (CC BY) license (https:// creativecommons.org/licenses/by/ $4.0 /)$.
1 Hematology and Clinical Immunology Unit, Department of Medicine, University of Padua, 35128 Padua, Italy; alessandro.cellini@studenti.unipd.it (A.C.); andrea.visentin@unipd.it (A.V.); massimilianoaf@gmail.com (M.A.F.); susanna.vedovato@gmail.com (S.V.); carmela.gurrieri@unipd.it (C.G.)

2 Veneto Institute of Molecular Medicine, Centro di Eccellenza per la Ricerca Biomedica Avanzata, 35129 Padua, Italy

3 Infective and Tropical Disease Unit, Padua University Hospital, 35128 Padua, Italy; serena.marinello@aopd.veneto.it

4 Anesthesiology and Intensive Care Unit, Padua University Hospital, 35128 Padua, Italy; ivo.tiberio@aopd.veneto.it

* Correspondence: livio.trentin@unipd.it; Tel.: +39-049-821-2298

+ These authors contributed equally to this work.

\begin{abstract}
Hemophagocytic Lymphohistiocytosis (HLH) is a rare but life-threatening disease that can occur either as a primary condition or as a consequence of a variety of triggers, including infectious diseases. Here we present a case of secondary HLH triggered by systemic Mycobacterium tuberculosis infection in a 59-year-old immunocompromised Hairy Cell Leukemia and previous SARSCoV2 infected patient. This case report underlines the role of Etoposide-based chemotherapy in treating the severe inflammation that is the defining factor of $\mathrm{HLH}$, suggesting how, even when such therapy is not effective, it may still give the clinicians time to identify the underlying condition and start the appropriate targeted therapy. Moreover, it gives insight on our decision to treat the underlying haematological condition with a BRAF-targeted therapy rather than purine analog-based chemotherapy to reduce the risk of future severe infections.
\end{abstract}

Keywords: hairy cell leukemia; hemophagocytic lymphohistiocytosis; Mycobacterium tuberculosis; SARS-CoV2; BRAF V600E

\section{Introduction}

Hemophagocytic Lymphohistiocytosis (HLH) is a rare but life-threating disease characterized by abnormal immune activation, which can clinically present with cytopenias, abnormal liver function, fever and splenomegaly. It can occur either as a primary condition or as a consequence of a variety of triggers, ranging from malignancies to infections, the former being most frequently represented by non-Hodgkin Lymphomas (NHL) and the latter by viral infections (most commonly EBV and HIV infections) with tuberculosis being a rare trigger for $\mathrm{HLH}$.

The vast majority of adult HLH cases belong to secondary HLH (sHLH), and the appropriate treatment should target the underlying pathological condition. However, triggering factors cannot sometimes be identified, and the severe inflammatory symptoms require immediate treatment $[1,2]$.

Herein we report a case of sHLH in an immunocompromised Hairy Cell Leukemia (HCL) and previous SARS-CoV2 infected patient, where a concurrent hematologic malignancy led us to treat it with chemotherapy according to the HLH-2004 protocol to no avail. Once miliary tuberculosis was identified as the triggering factor, appropriate treatment was started, and the patient's condition began to improve. 


\section{Case Presentation}

A 59-year-old man was transferred to the Padua University Hospital Haematology section for a fever of unknown origin and mild cytopenia. The patient had developed a mild fever and arthralgias two months prior to his presentation and was initially treated with Levofloxacin and steroids. The man was a social health care worker, and his medical history was notable for BRAF V600E mutated HCL [3,4], diagnosed in 2018 and never treated. He had no history of vaccination with the Bacillus Calmette-Guerin. On April 2020 he was diagnosed with severe SARS-CoV2 disease that required mechanical ventilation and prolonged high-dose corticosteroids. His clinical course infection was also complicated by invasive fungal infection and deep vein thrombosis. During the hospitalization related to the SARS-CoV2 infection, a QuantiFeron-TB Gold test was performed and resulted negative. In the months following the SARS-CoV2 infection, the patient suffered from recurrent parainfective arthritis, which was treated with a long-term low-dose steroid therapy.

On admission, his physical exam showed mild hepatomegaly and no evidence of ascites, jaundice or cutaneous erythematous rash. Blood tests were notable for bilinear cytopenia $\left(\right.$ WBC $1.26 \times 10^{9} / \mathrm{L}$, Neutrophils $0.9 \times 10^{9} / \mathrm{L}$, Monocytes $0.01 \times 10^{9} / \mathrm{L}$, Hemoglobin $90 \mathrm{~g} / \mathrm{L}$, Platelets $134 \times 10^{9} / \mathrm{L}$ ) and slight liver enzyme elevation (AST 71 U/L, n.v. 10-45 U/L; ALT $104 \mathrm{U} / \mathrm{L}$ n.v. 10-50 U/L), high C-reactive protein levels (150 mg/L, n.v. 0-6 mg/L) and procalcitonin levels (1.48 ug/L). Nasopharyngeal swab tested negative for SARS-CoV2. A CT scan revealed small lymph nodes (max $\varnothing 2 \mathrm{~cm}$ ), ground-glass opacities in the lung parenchyma, splenomegaly $(\varnothing 19 \mathrm{~cm})$, pleural and abdominal effusion (Supplementary Figure S1).

The patient was then treated with broad-spectrum antibiotics, antimycotics and high dose corticosteroids. Unfortunately, his clinical conditions failed to improve, as he developed spleen enlargement and his cytopenia progressively worsened. Subsequent blood tests showed an increase in the IL-2 soluble receptor $(44.270 \mathrm{kU} / \mathrm{L}, \mathrm{n} . \mathrm{v} .223-710 \mathrm{kU} / \mathrm{L})$, elevated ferritin levels (39.286 ug/L, n.v. 31-409 ug/L) with a decrease in its glycosylated fraction (12\%, n.v. 50-80\%) and a further increase in liver enzyme levels (Figure 1). A diagnosis of HLH was made, as the patient fulfilled 6 out of the 8 HLH-2004 criteria [5], and the search for triggering factors was started.

Blood, urine and sputum cultures were negative for most common bacteria and fungi. Galactomannan, $\beta$-D-glucan and serological tests were negative (including serologies for HIV 1 and 2, hepatitis C and hepatitis B), as well as tests for anti-nucleus antibodies and rheumatoid factor. A trephine bone marrow biopsy confirmed the HCL diagnosis and excluded histological transformation to a high-grade B-cell lymphoma or T-cell nonHodgkin lymphoma.

The patient's condition started to worsen rapidly, and he required transfer to the intensive care unit for vasopressor support and mechanical ventilation. At this time, a QuantiFeron-TB Gold test became "indeterminate-positive", and prolonged blood culture (sample collected near the date of the patient's admission, result obtained two months after collection) revealed a Mycobacterium tuberculosis complex (MTC) [6]. Cultures of the pleural effusion were negative, also for MTC. The presence of active neoplasia and positive blood culture ruled out the diagnosis of Adult-Onset Still's Disease [7], and the patient was diagnosed with sHLH syndrome due to disseminated tuberculosis [8]. The man was initially treated with steroids, etoposide and rituximab to switch off the cytokine storm released by macrophages, with mild improvement, and subsequently with antiMTC therapy (isoniazid $150 \mathrm{mg}$ twice daily, rifampicin $300 \mathrm{mg}$ twice daily, ethambutol $1200 \mathrm{mg}$ daily, pyrazinamide $500 \mathrm{mg}$ daily. Pyrazinamide therapy was introduced after improvement of hepatic enzyme levels) with a quick drop in ferritin levels and liver enzymes (at the start of anti-MTC therapy ALT 365 U/L, AST 109 U/L; both parameters went back to normal values within 15 days following the trend depicted by the total bilirubin value), as well as improvement of haematological parameters (Figure 1). His recovery was complicated by invasive fungal infection, defined as a probable invasive aspergillosis due to the repeatedly positive Galactomannan blood tests and suggestive 
lung CT findings, and fever due to suspect immune reconstitution syndrome [9]. Once his condition improved, treatment for his HCL was started (Rituximab-Vemurafenib), and he was subsequently transferred to a rehabilitation facility.

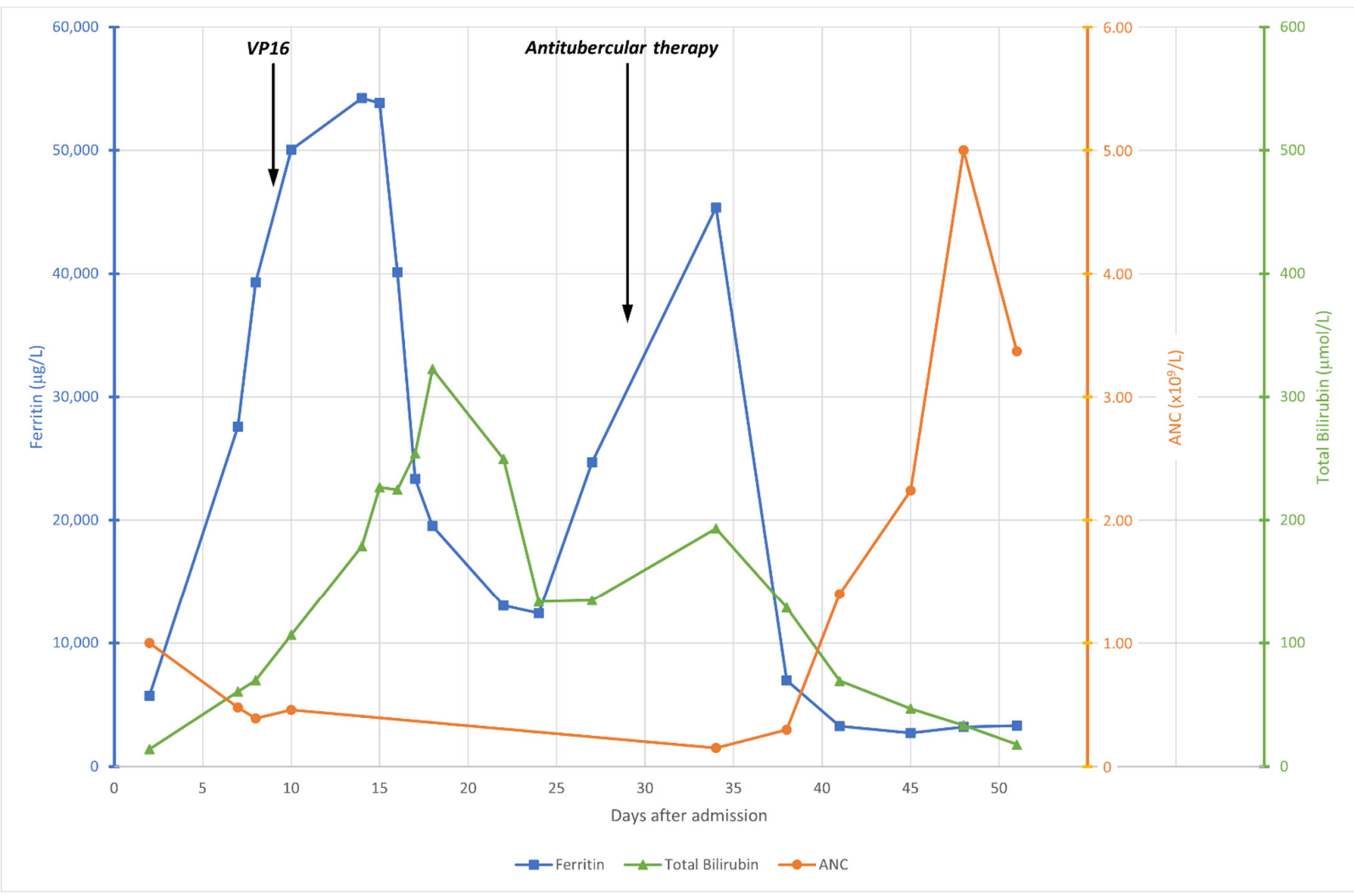

Figure 1. Ferritin (blue) total birilubin (green) and neutrophil count (orange) trend during the patient's hospital stay (days after hospitalization). The black arrows indicate the two time points at which Etoposide (day 9) and antitubercolar treatments (day 29) were administered. ANC: Absolute Neutrophil Count; VP16: Etoposide.

\section{Discussion}

HLH is a rare, life-threatening immunological disorder. Due to its rapid onset, menacing symptoms and potential end organ damage, it requires prompt diagnosis and treatment. Our patient fulfilled 6 out of 8 diagnostic criteria for HLH according to the HLH-2004 protocol, and thus his clinical presentation was deemed highly suspicious for HLH. Moreover, he presented with hyperferritinemia and a low percentage of glycosylated ferritin, which has been proven to be a highly specific diagnostic marker and a poor prognostic marker for HLH $[10,11]$.

While the diagnostic workup pointed towards HLH early on during the patient's hospital stay, the search for a triggering factor proved to be complicated. Primary HLH was ruled out mainly because of the patient's age.

The patient was affected by a HCL which has rarely reported to be the triggering factor for sHLH, but, on the other hand, it is widely known as a strong immunosuppressive malignancy [12]. This, combined with the prolonged steroid therapy and the unknown consequences of a severe SARS-CoV-2 infection, led the diagnostic path towards a secondary infectious cause of HLH.

Mycobacterium tuberculosis infection is a known rare trigger of sHLH [13] in immunocompromised patients. The man's occupation, his prolonged steroid therapy and HCL were all significant risk factors for MTB infection, which developed atypically without 
pulmonary lesions and without detection of MTB-DNA on bronchial wash fluids. The only evidence of MTB infection found has been positive blood cultures, as lymph-node biopsy could not be performed because of the involved lymph-node anatomical location and the patient's general conditions.

As a triggering factor was not initially found and the patient's conditions were rapidly worsening, we started chemotherapy according to the HLH-2004 protocol, with high dose dexamethasone and etoposide, obtaining a partial and limited response, as shown by the mild decrease of liver function enzymes and bilirubin right after the first administration of etoposide (Figure 1). While this line of therapy proved to be ineffective, as the patient had to be admitted to the ICU shortly after, it may have given us the necessary time to detect MTC on blood cultures and subsequently start with the appropriate treatment.

Given the important role played by HCL-derived immunosuppression in this patient's presentation, we decided to treat the underlying haematological disorder once his clinical condition improved. Considering the important monocytopenia and neutropenia, and the consequential higher risk for opportunistic infections, we preferred to treat the disease with Vemurafenib rather than purine analog 2CDA (Cladribine), as treatment with Cladribine is associated with higher toxicity towards the immune system, especially regarding the $\mathrm{T}$ cell compartment $[14,15]$.

The case we presented points out the role of MTC infections in immunocompromised patients as a triggering factor for sHLH, even in the absence of typical pulmonary lesions or a history suggestive of primary MTC infection. MTB infection in our patient was recent, as a QuantiFeron-TB Gold test was negative during his first hospitalization, and it is unknown whether long-COVID complications and/or immunosuppression triggered by HCL might have favored the development of miliary MTC disease. Moreover, is that HLH-directed chemotherapy based on high dose corticosteroids and etoposide, other than being the first appropriate treatment when a triggering factor cannot be found, can give the clinicians time to identify rare and potentially treatable underlying disease. As such, the search for the triggering factor should not be stopped, even when the patient's conditions are worsening, and chemotherapy has already been started.

Supplementary Materials: The following are available online at https:/ / www.mdpi.com/article/10.3 390/app12020564/s1, Figure S1: Thoracic CT scans before and after the start of antitubercular therapy.

Author Contributions: A.C., S.V. and M.A.F. treated patient and wrote the letter; A.V. treated the hairy cell leukemia; C.G. and L.T. treated the patient and revised the letter; S.M. managed MTC, I.T. managed the complications of the HLH. All authors have read and agreed to the published version of the manuscript.

Funding: This work was supported by funds from Associazione Italiana per la Ricerca sul Cancro (A.I.R.C.) projects to L.T. (IG-25024) and "Ricerca per Credere nella Vita" RCV odv.

Institutional Review Board Statement: The study was conducted according to the guidelines of the Declaration of Helsinki.

Informed Consent Statement: Informed consent was obtained from all subjects involved in the study.

Acknowledgments: We would like to thank our nurses for their pivotal contribution in the management of the patient.

Conflicts of Interest: The authors declare no conflict of interest.

\section{References}

1. Soy, M.; Atagündüz, P.; Atagündüz, I.; Sucak, G.T. Hemophagocytic lymphohistiocytosis: A review inspired by the COVID-19 pandemic. Rheumatol. Int. 2021, 41, 7-18. [CrossRef] [PubMed]

2. La Rosée, P.; Horne, A.; Hines, M.; von Bahr Greenwood, T.; Machowicz, R.; Berliner, N.; Birndt, S.; Gil-Herrera, J.; Girschikofsky, M.; Jordan, M.B.; et al. Recommendations for the management of hemophagocytic lymphohistiocytosis in adults. Blood 2019, 133, 2465-2477. [CrossRef] [PubMed] 
3. Visentin, A.; Imbergamo, S.; Trimarco, V.; Pravato, S.; Gargarella, L.R.; Frezzato, F.; Scapinello, G.; Bertorelle, R.; Piva, E.; Facco, M.; et al. Ibrutinib in relapsed hairy cell leukemia variant: A case report and review of the literature. Hematol. Oncol. 2020, 38, 823-826. [CrossRef]

4. Tiacci, E.; Schiavoni, G.; Forconi, F.; Santi, A.; Trentin, L.; Ambrosetti, A.; Cecchini, D.; Sozzi, E.; di Celle, P.F.; Di Bello, C.; et al. Simple genetic diagnosis of hairy cell leukemia by sensitive detection of the BRAF-V600E mutation. Blood 2012, 119, $192-195$. [CrossRef]

5. Henter, J.I.; Horne, A.C.; Aricó, M.; Egeler, R.M.; Filipovich, A.H.; Imashuku, S.; Ladisch, S.; McClain, K.; Webb, D.; Winiarski, J.; et al. HLH-2004: Diagnostic and therapeutic guidelines for hemophagocytic lymphohistiocytosis. Pediatr. Blood Cancer 2007, 48, 124-131. [CrossRef]

6. Ceia, F.; Santos-Silva, A.; Alves, J.; Silva-Pinto, A.; Oliveira, O.; Carvalho, A.C.; Ramos, A.; Carvalho, T.; Sarmento, A.; Duarte, R. Mycobacterial blood cultures in the diagnosis of tuberculosis in human immunodeficiency virus-infected patients: Are they useful? Clin. Microbiol. Infect. 2019, 25, 264-265. [CrossRef]

7. Mimura, T.; Kondo, Y.; Ohta, A.; Iwamoto, M.; Ota, A.; Okamoto, N.; Kawaguchi, Y.; Kono, H.; Takasaki, Y.; Takei, S.; et al. Evidence-based clinical practice guideline for adult Still's disease. Mod. Rheumatol. 2018, 28, 736-757. [CrossRef] [PubMed]

8. Ravelli, A.; Minoia, F.; Davì, S.; Horne, A.; Bovis, F.; Pistorio, A.; Aricò, M.; Avcin, T.; Behrens, E.M.; De Benedetti, F.; et al. 2016 Classification Criteria for Macrophage Activation Syndrome Complicating Systemic Juvenile Idiopathic Arthritis A European League Against Rheumatism/American College of Rheumatology/Paediatric Rheumatology International Trials Organisation Collaborative Initiative European League Against Rheumatism, and the Paediatric Rheumatology International Trials Organisation. Arthrits Rheumatol. 2016, 68, 566-576. [CrossRef]

9. Lanzafame, M.; Vento, S. Tuberculosis-immune reconstitution inflammatory syndrome. J. Clin. Tuberc. Other Mycobact. Dis. 2016, 3, 6-9. [CrossRef]

10. Fardet, L.; Coppo, P.; Kettaneh, A.; Dehoux, M.; Cabane, J.; Lambotte, O. Low Glycosylated Ferritin, a Good Marker for the Diagnosis of Hemophagocytic Syndrome. Arthritis Rheumatol. 2008, 58, 1521-1527. [CrossRef] [PubMed]

11. Nabergoj, M.; Marinova, M.; Binotto, G.; Brugnaro, L.; Zaninotto, M.; Plebani, M.; Semenzato, G.; Vianello, F. Diagnostic and prognostic value of low percentage of glycosylated ferritin in acquired hemophagocytic lymphohistiocytosis: A single-center study. Int. J. Lab. Hematol. 2017, 39, 620-624. [CrossRef] [PubMed]

12. Kraut, E. Infectious complications in hairy cell leukemia. Leuk. Lymphoma 2011, 52 (Suppl. 2), 50-52. [CrossRef]

13. Rathnayake, P.V.T.M.; Kularathne, W.K.S.; De Silva, G.C.V.; Athauda, B.M.S.B.; Nanayakkara, S.N.N.K.; Siribaddana, A.; Baminiwatte, D. Disseminated tuberculosis presenting as hemophagocytic lymphohistiocytosis in an immunocompetent adult patient: A case report. J. Med. Case Rep. 2015, 9, 294. [CrossRef] [PubMed]

14. Maitre, E.; Cornet, E.; Troussard, X. Hairy cell leukemia: 2020 update on diagnosis, risk stratification, and treatment. Am. J. Hematol. 2019, 94, 1413-1422. [CrossRef] [PubMed]

15. Tiacci, E.; De Carolis, L.; Simonetti, E.; Capponi, M.; Ambrosetti, A.; Lucia, E.; Antolino, A.; Pulsoni, A.; Ferrari, S.; Zinzani, P.L.; et al. Vemurafenib plus Rituximab in Refractory or Relapsed Hairy-Cell Leukemia. N. Engl. J. Med. 2021, 384, 1810-1823. [CrossRef] 